\title{
Effect of signaling extra unconditioned stimuli on autoshaping
}

\author{
M. J. GODDARD and H. M. JENKINS \\ McMaster University, Hamilton, Ontario, Canada
}

\begin{abstract}
Acquisition to a target conditioned stimulus (CS) is prevented when extra, unsignaled unconditioned stimuli (USs) are presented with sufficient frequency to remove contingency between target CS and US. Acquisition occurs, however, when the extra USs are signaled by another CS. According to the Rescorla-Wagner theory, signaling reduces contextual conditioning, which otherwise prevents acquisition. Results of Experiment 1 led to the rejection of a rival explanation derived from scalar expectancy theory by showing that acquisition does not occur when only half of the extra USs are signaled. The results of Experiment 2 were, however, contrary to the RescorlaWagner theory because they showed equivalent acquisition when the stimulus used to signal the extra USs was also present concurrently with the target CS. Signaling may exert its effect by converting the intertrial interval to CS-.
\end{abstract}

The acquisition of conditioned responding, normally produced by paired presentations of a conditioned stimulus (CS) and an unconditioned stimulus (US), is prevented when extra USs occur at a rate sufficient to reduce the contingency between CS and US to zero (Ayres, Benedict, \& Witcher, 1975; Dweck \& Wagner, 1970; Gamzu \& Williams, 1973; Rescorla, 1968, 1972). When contingency is removed by the addition of the US presentations, the paired CS-US presentations, which are not themselves altered, lose their ability to bring about conditioned responding. Among the theories that attempt to explain the process by which extra USs interfere with the effectiveness of a CS-US pairing, two are of particular concern to the present paper: the Rescorla-Wagner theory (Rescorla \& Wagner, 1972; Wagner \& Rescorla, 1972) and Scalar Expectancy Theory (Gibbon, 1981; Gibbon \& Balsam, 1981).

According to the Rescorla-Wagner theory, the extra USs interfere with the effectiveness of CS-US presentations by causing an association to form between the prevailing contextual stimuli afforded by the conditioning environment and the US. Presentations of the CS are considered to be compound presentations of CS and context in which context competes with the CS as a signal for the US. In the case of zero contingency, in which the rate of US presentation outside of the CS equals its rate when the CS is present, the equations of the RescorlaWagner theory show that the context acquires all of the available signal value, while the CS becomes completely neutralized. Application of these equations also shows that if all USs are signaled by a CS, the context eventually

This research was supported by a grant from the National Science and Engineering Research Council of Canada (NSERC) to the second author and by an NSERC postgraduate scholarship to the first author. We thank S. Siegel for comments on the manuscript.

Reprint requests should be sent to $H$. M. Jenkins, Department of Psychology, McMaster University, Hamilton, Ontario L8S 4K1, Canada. has zero signal value whereas the CS has all the available signal value. The theory predicts that if the extra USs in the zero contingency case were signaled by a second CS, the target CS would gain associative strength. Furthermore, if the second CS were well conditioned before the target CS was presented, no interference from extra USs would be expected.

Recent experiments (Durlach, 1984; Rescorla, 1984) have led to the view that signaling extra USs would not entirely prevent contextual conditioning because the context receives secondary reinforcement from the CS. Even so, the prediction remains (Durlach, 1983) that signaled USs produce weaker conditioning of the context than do unsignaled USs and could, therefore, yield acquisition under zero contingency.

A different explanation for interference by extra USs is provided by scalar expectancy theory (SET). According to SET, the critical variable for conditioning is the ratio of the average waiting time for a US in the context to the average waiting time for a US when the CS is present. This ratio has been referred to as relative waiting time (RWT) (Jenkins, Barnes, \& Barrera, 1981). According to SET, a ratio in excess of 1 is required for the emergence of conditioned responding to the CS. The introduction of extra USs at a rate sufficient to reduce the CS-US contingency to zero equates the overall waiting time for the US in the context to the waiting time for the US in the CS. The RWT in the zero contingency case is, therefore, equal to 1 . According to SET, it is not competition between the context and the CS as signals of the US that accounts for the effect of zero contingency. It is, rather, the effect of extra USs on the ratio of waiting times. Because the average waiting time in the context and that in the target CS are not altered by the signaling of the extra USs, SET predicts that the effect of extra USs is no different whether signaled or unsignaled by a second CS. Several experiments have produced results supporting this conception (Balsam, 1982; Jenkins, 1984; 
Jenkins et al., 1981; Jenkins \& Lambos, 1983; Jenkins \& Shattuck, 1981; LoLordo \& Randich, 1981).

Jenkins et al. (1981, Experiment 13) did not obtain significantly less acquisition to a target CS when extra USs were signaled as compared to when they were unsignaled, but such an effect was obtained by Durlach (1983), who used more prolonged target CS conditioning. Durlach's finding that acquisition occurred to the target CS when the extra USs were signaled, but not when they were unsignaled, supports the Rescorla-Wagner theory. There is, however, an interpretation of this result that would not be incompatible with SET, namely, that what appears to be conditioning to the target CS when extra USs are signaled is actually generalized responding from the CS used to signal the extra USs to the target CS.

Durlach (1983) found acquisition to a keylight target CS when the extra USs were signaled by a different keylight or a tone. The tone was used in order to minimize generalization, but generalization remains a possibility. Tone and keylight are alike in being briefly presented stimuli; tones used as signals of food have been observed in this laboratory to produce pecklike movements in pigeons, and Durlach's procedure involved intermixed, reinforced presentations of the tone and keylight, which might enhance generalization. Experiment 1 examines a unique prediction that follows from SET if it is the case that generalization is responsible for responding to the target CS when the extra USs are signaled by a second CS.

\section{EXPERIMENT 1}

An interesting prediction from SET that has received experimental support (Jenkins et al., 1981, Experiment 13) is that conditioning produced by a CS-US presentation is independent of the fraction of US presentations signaled by the CS. This prediction follows from SET as directly, and for the same reason, as does the prediction of equal interference from signaled and unsignaled USs. Again, the critical variable is RWT, which is not altered when only some, rather than all, USs are signaled. The unique prediction from SET is that, if responding to the target CS is due to generalization from the CS used to signal the extra USs, generalization should occur equally whether all or only a fraction of the USs are signaled. In contrast, the Rescorla-Wagner theory predicts less acquisition to the target CS when only a fraction, rather than all, of the extra USs are signaled. Experiment 1 repeated the groups run in Durlach's (1983) experiment and added a group in which only $50 \%$ of the extra USs were signaled.

\section{Method}

Subjects. The subjects were 30 naive, unsexed White King pigeons maintained at $75 \%$ of their free-feeding weights. They were housed in individual cages with free access to water and grit.

Apparatus. Six modified Lehigh Valley pigeon chambers were used. Each was equipped with a speaker, a solenoid-operated feeder, a ventilating fan, and two response keys. The left-hand key was covered; only the right-hand key was used. The center of the key was $20 \mathrm{~cm}$ above the chamber floor and offset from the midline of the front panel by $1.6 \mathrm{~cm}$. During keylight pretraining, the autoshaping stimulus consisted of a 2.5 -cm circle backlighted by a white lamp encased in a blue plastic cap. The target CS, introduced in the main training phase, was a lighted circular area $2.5 \mathrm{~cm}$ in diameter, with an $X$ superimposed on it by the use of black masking tape applied to the back of the key. The target CS was backlighted by a white lamp. Operation of the feeder made mixed grain available through a $5.7 \times 5 \mathrm{~cm}$ opening centered on the front panel. A white lamp illuminated the feeder opening during feeder operation only. Across the feeder opening was a photocell circuit, which was interrupted when the pigeon put its head in the food-tray opening. The chamber was continuously illuminated by a row of three white lamps mounted across the top of the front panel, $33 \mathrm{~cm}$ from the chamber floor and $3 \mathrm{~cm}$ from the chamber ceiling. The lamps were enclosed in housings that directed the light to the ceiling. The keylight, feeder-tray light, and houselights were provided by miniature white bulbs (GE1829). A 94-dB 2000-Hz tone was used to signal extra USs. The tone was delivered by a speaker located on the lower left of the front panel. Masking noise was provided by the ventilating fans. Programming and recording of experimental events were accomplished by means of a Commodore PET computer located in an adjacent room.

Procedure. Subjects were first trained to eat from the food magazine. When first placed in the chamber, they found grain available in the raised food tray. After they had taken grain, an automatically programmed schedule of food delivery was used in which the tray-up period and interfeeding interval for each US presentation were timed from the interruption of the photocell beam. In the first session, 10 food-tray presentations were effected with a decreasing tray-up period, averaging $8.8 \mathrm{sec}$, and decreasing interfeeding intervals, averaging $54 \mathrm{sec}$. The same tray-delivery schedule was used in the second session until the tray-up period reached 5 sec. Subjects were then given 10 additional 5 -sec food presentations with 30-sec interfeeding intervals to complete the session. In the next two sessions, subjects received 445 -sec food presentations with a mean interfeeding interval of $1 \mathrm{~min}$.

Subjects were then given 1220 -min sessions in which $2010-\mathrm{sec}$ blue keylight presentations were followed immediately by $5 \mathrm{sec}$ access to grain. The session was divided into 8015 -sec periods. Trials were programmed randomly for each group of subjects with the constraint of a minimum intertrial interval (ITI) of $15 \mathrm{sec}$. Keylight pretraining was used as a basis for assigning subjects to groups matched on response rate. Two subjects were dropped from the experiment because they responded infrequently.

The remaining 28 subjects were then given 1620 -min sessions of training, with the tone used to signal the extra USs in the main training phase. In each session, 20 10-sec tones were followed immediately by $5 \mathrm{sec}$ access to grain. Trials were programmed randomly for each group of subjects with the constraint of a minimum ITI of $15 \mathrm{sec}$. One subject was dropped because of a persistent failure to eat from the feeder during tone pretraining.

During the main training phase, all subjects were given identical autoshaping on the target CS (10-sec presentations of the $X$ stimulus). Daily sessions were 20 min long and contained 12 trials on which the target CS was presented. Three of these trials were reinforced by 5 sec access to grain, and 9 were unreinforced. For Group No Extra $(n=6)$, these were the only events programmed to occur during the session. For the other three groups, 17 extra 5-sec food presentations were given during each session. In Group Signaled $(n=7)$, extra food presentations were signaled by the 10-sec tone. In Group Unsignaled $(n=7)$, extra food presentations were unsignaled. In Group Partial $(n=7), 9$ food presentations were signaled by the tone and the remaining 8 were unsignaled. Trial events were programmed randomly with the constraint of a minimum ITI of $15 \mathrm{sec}$. 


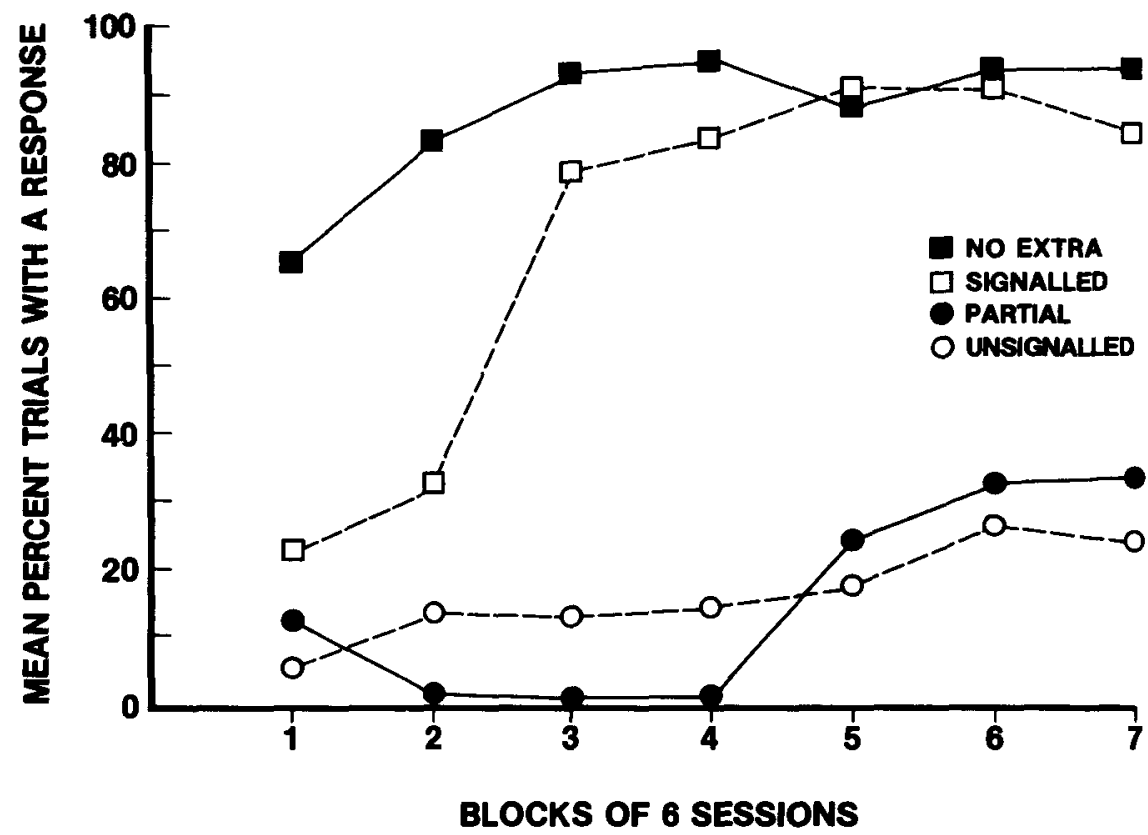

Figure 1. Mean percent of trials with a response during target CS training in Experiment 1.

\section{Results and Discussion}

The mean percent of target CS trials on which at least one response occurred is shown for 6-session blocks in Figure 1. Table 1 shows the mean percent and mean rate of response, with standard errors, for the last 18 sessions. During these sessions, Group No Extra and Group Signaled showed relatively high levels of responding to the target CS compared with lower and more variable responding in Group Unsignaled and Group Partial. In both percent of trials responded to and response rate, Group No Extra differed significantly from Group Unsignaled (on percent, $U=1, p<.005$; on rate, $U=2$, $p<.005)$. Group Signaled also differed significantly from Group Unsignaled (on percent, $U=6, p<.025$; on rate, $U=4, p<.005$ ). Group Partial did not differ from Group Unsignaled (on percent $U=21, p>.05$; on rate, $U=20, p>.05$ ).

The results of Experiment 1 replicate Durlach's (1983) findings by showing significantly greater responding to the target CS when extra USs are signaled rather than unsignaled. The results provide no support, however, for the possibility that this effect is consistent with SET and arises from stimulus generalization between the signaling and target CS. Contrary to this prediction, subjects with half of the extra USs signaled showed no more acquisition to the target CS than did subjects with none of the extra USs signaled. Although this result does not eliminate the possibility that stimulus generalization is involved, it is important because it shows that SET is incapable of accounting for the effect of signaling extra USs on responding to a noncontingent target CS. The results of this experiment are compatible not only with the Rescorla-Wagner model (Rescorla \& Wagner, 1972), but with all formulations that postulate competition between the CS and the context (e.g., Mackintosh, 1975; Pearce \& Hall, 1980; Wagner, 1978). The results do not, however, provide direct evidence that a context-US association acting concurrently with the reference $\mathrm{CS}$ is the source of interference.

\section{EXPERIMENT 2}

Signaling extra USs can be thought of as introducing two conditions not present when extra USs are unsignaled. The one regarded as critical by the Rescorla-Wagner theory, and by other context-competition theories, is that the stimulus condition that accompanies the extra USs (context plus the second CS) is different from the stimulus condition that accompanies the target CS (context alone). The other new condition, to which little attention has been paid, is that the stimulus during the ITI (context alone) is now uniformly associated with the absence of US presentations and may therefore be regarded as a CS- . Instead of a two-component session consisting of a target CS and no target CS with equal probabilities of the US, the session is divided into three components: a signaling CS with a high probability of US presentation, the ITI with zero probability of US presentation, and the target

Table 1

Mean Percent and Rate of Response (per Second) to Target CS During Last 18 Sessions of Training in Experiment 1

\begin{tabular}{lcccc}
\hline \multicolumn{1}{c}{ Group } & Percent & \multicolumn{1}{c}{$S E$} & Rate & $S E$ \\
\hline No Extra $(n=6)$ & 92.9 & \pm 6.5 & 1.6 & \pm .4 \\
Signaled $(n=7)$ & 89.4 & \pm 2.3 & 0.8 & \pm .4 \\
Unsignaled $(n=7)$ & 22.7 & \pm 13.7 & 0.2 & \pm .1 \\
Partial $(n=7)$ & 30.2 & \pm 14.9 & 0.3 & \pm .1 \\
\hline
\end{tabular}

Note-SE $=$ standard error. 
CS with an intermediate probability of US presentation. Thus, signaling the extra USs introduces a contrast in US probability between the ITI and the target CS. This contrast could be responsible for acquisition to the target CS when extra USs are signaled.

These two effects of signaling extra USs were separated in Experiment 2 by means of the design shown in Figure 2. The treatments of Groups No Extra, Unsignaled, and Signaled were the same as in Experiment 1. In Group CS- , on the other hand, a tone was constantly present during the ITI. The tone went off to signal the extra USs and also when the target CS was presented. In Group CS- , as in Group Unsignaled, the same stimulus condition accompanied the extra USs and the target CS. Therefore, if competition between a context-US association and a target CS-US association is critical, this group should show no more (actually less) responding to the target CS than should Group Unsignaled. Less responding in Group CS- is predicted by context competition theories because the presence of the tone during the ITI would protect the tone-off stimulus from extinction during the ITI. On the other hand, if the critical new condition introduced by signaling is the establishment of a nonreinforced ITI stimulus, acquisition of responding to the target CS in Group CS - should occur as it is known to do under the conditions for Group Signaled. These predictions were tested in Experiment 2.

\section{Method}

Subjects and Apparatus. The subjects were 23 naive, unsexed White King pigeons maintained at $75 \%$ of their free-feeding weights. The apparatus was the same as that used in Experiment 1 with the exception of changes noted below in the location and size of the keylight pretraining stimulus.

Procedure. The following changes in the procedure of Experiment 1 were made. Ten, rather than 12 , sessions of autoshaping to a blue keylight were used in the keylight pretraining phase. In order to reduce possible stimulus generalization from the blue keylight pretraining stimulus to the target $\mathrm{CS}$, the circle of blue light was reduced to $7 \mathrm{~mm}$ in diameter from $2.5 \mathrm{~cm}$, and it was presented on the left-hand key rather than on the right-hand key where the target CS was presented.

Groups Unsignaled, Signaled, and No Extra each received pretraining in which the tone was used to signal the US. Pretrain-

NO EXTRA

UNSIGNALLED

\section{SIGNALLED}

cs-

Figure 2. Design of Experiment 2. $T$ refers to tone, $X$ to target CS, and dots to USs. ing parameters were similar to those of Experiment 1, but 15, rather than 16 , sessions were run and 10 , rather than 20 , trials were programmed in each session. Tone pretraining for Group CS- was designed to make the absence of tone an excitatory stimulus for US presentation, and the presence of the tone a CS- signaling nonoccurrence of the US. The 20 -min session was divided into 80 15-sec blocks. A block could contain a 10-sec CS during its first $10 \mathrm{sec}$, or a US in the last $5 \mathrm{sec}$, but not both. A block in which either a CS or US occurred was followed by at least one empty block. Subject to these constraints, CSs and USs were assigned to blocks randomly.

The main training phase was as described in Experiment 1 with the exception of Group CS-, in which extra USs were signaled by the absence of the tone. The tone was turned off $10 \mathrm{sec}$ before extra USs were presented and was turned back on at the onset of the US. The tone was also turned off during the target CS. Trials were programmed randomly for each group in each session with the constraint of a minimum ITI of $15 \mathrm{sec}$.

Two subjects were dropped from the experiment because of infrequent responding to the keylight during pretraining. The remaining 21 subjects were assigned to groups matched as closely as possible for rate of responding to the blue keylight. Each group contained 6 subjects, except that Group No Extra contained 3 subjects.

\section{Results and Discussion}

The mean percent of target CS trials on which at least one response occurred is shown for 6-session blocks in Figure 3. Table 2 shows the mean percent and mean rate of response, with standard errors, for the last 18 sessions. During these sessions, Group No Extra responded at the highest level. Group Signaled and Group CS- responded at similar, intermediate levels, whereas Group Unsignaled showed almost no responding. In both percent of trials responded to and rate of response, Group CS- was significantly higher than Group Unsignaled (on percent, $U=6, p<.05$; on rate, $U=6, p<.05$ ). Group Signaled also responded at a significantly higher level than Group Unsignaled (on percent, $U=0, p<.005$; on rate, $U=0, p<.005$ ). Group Signaled and Group CSdid not differ significantly from each other on either measure (on percent, $U=15, p>.05$; on rate, $U=15$, $p>$.05).

Responding to the target CS was at a lower level in Experiment 2 than in the comparable groups of Experiment 1 . The most plausible explanation for reduced target CS responding lies in the keylight stimulus to which all birds were first autoshaped. In Experiment 2 an attempt was made to reduce generalization from this pretrained stimulus (see Apparatus section) to the target $\mathrm{CS}$, and these changes may have been responsible for reduced target CS responding.

The results of Experiment 2 show, in agreement with the findings of Durlach (1983) and Experiment 1, that signaling extra USs allows acquisition to occur despite a zero contingency between the target CS and US. The new finding of Experiment 2 is that the increase in responding to the target CS, which results when extra USs are signaled, does not depend on the ability of the second CS to prevent conditioning of the stimuli that accompany the target CS. In Group CS-, the same stimuli accompanied 


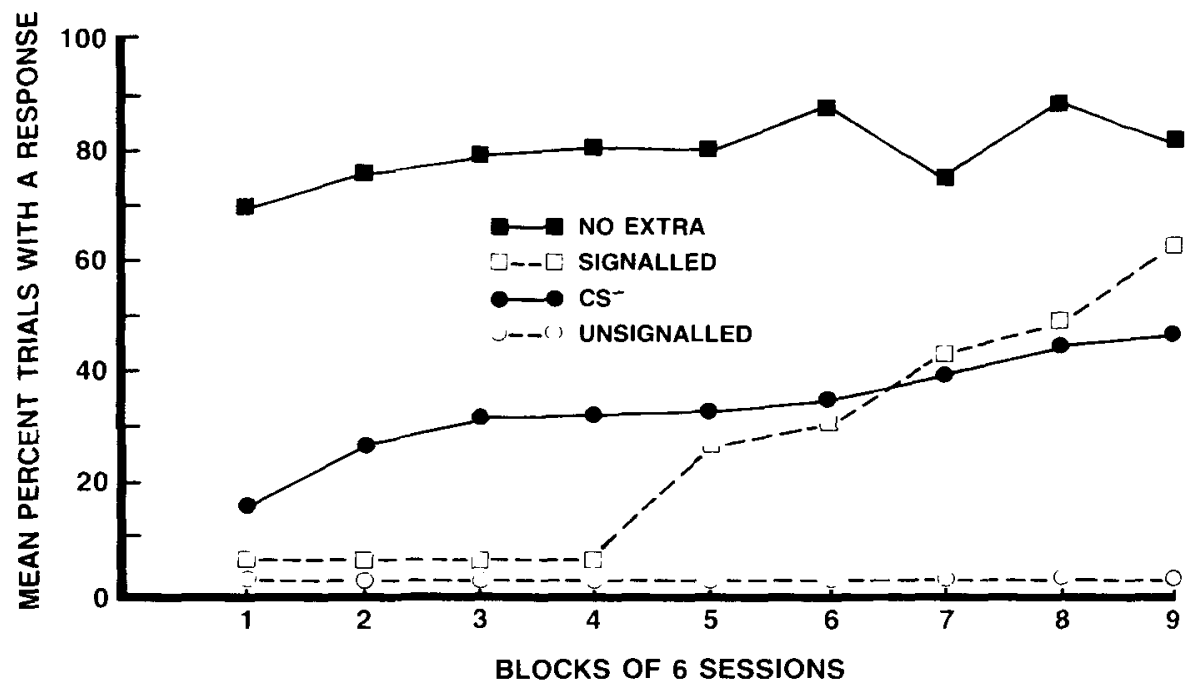

Figure 3. Mean percent of trials with a response during target CS training in Experiment 2.

the extra USs and the target CS, yet target CS responding was as great as it was when the stimulus conditions signaling the extra USs were different from those accompanying the target $C S$. These results suggest that the most important consequence of signaling the extra USs was to introduce a contrast between the nonreinforced intertrial stimulus and the reinforced target CS.

Other possible accounts for the performance of Group CS- need to be considered. Tone offset, acting over a trace interval, might be the effective stimulus for the extra USs rather than the absence of the tone. Because the stimulus during the interstimulus interval is different from the stimulus during the ITI, trace conditioning may be especially robust, as has been demonstrated in previous research (Kaplan \& Hearst, 1982; Rescorla, 1982). This possibility is, however, not promising, because tone offset also precedes target CS presentation by the same trace interval and would be expected to compete with the target CS no less effectively than would the absence of the tone.

An interesting possibility is that the associative strength accruing to the reference CS in Group CS- is the result not of an association between the target CS and US, but of a within-compound association between the highly excitatory tone absence and the target CS. The development of within-compound associations has been demonstrated in several recent experiments (e.g., Rescorla \& Colwill, 1983; Rescorla \& Durlach, 1981). The conditions in Group CS- do not, however, appear to be favorable to the formation of within-compound associations. There is evidence that within-compound associations are attenuated both when a US follows the compound stimulus presentation and when there are separate presentations of one of the two components before and after compound stimulus presentation (Rescorla \& Durlach, 1981). Both of these conditions are present in Group CS- in Experiment 2 . On $25 \%$ of the trials a US follows the compound of tone absent plus target CS, and within each session there are 17 separate tone-absent presentations that are not accompanied by the target CS. It is doubtful, therefore, that a within-compound association is responsible for the emergence of responding to the target CS.

Another possibility is that the excitatory, tone-absent stimulus facilitated responding to the target $C S$ with which it was paired. The evidence, however, goes against the existence of a facilitatory effect of this kind in autoshaping. Rescorla (1985, p. 313) tested for facilitation due to the pairing of a separately reinforced noise stimulus with a keylight stimulus and found none. There is no reason to expect a different result when the excitatory stimulus is tone absent.

\section{GENERAL DISCUSSION}

The present results replicate Durlach's (1983) finding that signaled extra USs interfere less with target CS acquisition than do unsignaled USs when the target CS and US are noncontingent. On the surface, this finding is contrary to SET, which holds that signaled and unsignaled USs have equal effects on target CS acquisition because of equal impact on relative waiting time. The finding would not be critical, however, if responding to the target CS were actually the result of generalization from the signaling to the target CS, and if SET provided an account of the conditioning of the signaling CS. The results

Table 2

Mean Percent and Rate of Response (per Second) to Target CS During Last 18 Sessions of Training in Experiment 2

\begin{tabular}{lccccc}
\hline \multicolumn{1}{c}{ Group } & Percent & $S E$ & Rate & $S E$ \\
\cline { 1 - 2 } No Extra $(n=3)$ & 81.6 & \pm 17.3 & 0.7 & \pm .3 \\
Signaled $(n=6)$ & 51.6 & \pm 17.5 & 0.7 & \pm .4 \\
Unsignaled $(n=6)$ & 0 & 0 & 0 & 0 \\
CS- $(n=6)$ & 43.4 & \pm 19.6 & 1.3 & \pm 1.0 \\
\hline
\end{tabular}

Note $-S E=$ standard error. 
of Experiment 1 eliminate this possibility by showing that under conditions in which SET must predict equal generalization, target CS acquisition was significantly poorer in a group with half of the extra USs signaled than in a group with all extra USs signaled. There are indications that SET makes the wrong prediction whenever a stimulus is introduced that establishes some portion of the conditioning session as an S-. This was the case in experiments by Farley (1980) and Brandon (1981). The fault seems to lie in the assumption that waiting time in a CS is compared with an average waiting time in the session without regard to differences in waiting times associated with different stimuli.

It also appears increasingly likely that the RescorlaWagner theory fails to represent adequately the effect of introducing a contrast between a stimulus predicting no US presentation and the higher probability of a US associated with the target CS. Such a contrast was introduced in Experiment 2 under conditions in which the Rescorla-Wagner theory predicts no acquisition to the target CS. The theory predicts no acquisition because the stimulus condition accompanying extra USs also accompanied the target CS. Interference should therefore have prevented acquisition no less than when extra USs were unsignaled. The result was, however, development of conditioned responding to the target $\mathrm{CS}$ as strongly as when signaling the extra USs should have prevented competition between the target CS and concurrently presented stimuli (context alone). Recent experiments showing that CS+ presentations can condition context more than CSpresentations (Rescorla, 1984) and that they can interfere with acquisition of responding to a target CS (Durlach, 1984) are not inconsistent with an interpretation that signaling extra USs established a contrast in US probability between the ITI and the target CS.

The results reported by Jenkins and Lambos (1983) complement the present results by showing that in the absence of a contrast between the conditions of US presentation in the ITI and the target CS, signaling extra USs does not affect their ability to interfere with maintenance of responding to a target CS. In their experiment, signaling the extra USs did not introduce a discriminated period of nonreinforcement because the signal occupied the entire time between target CS presentations. It now appears that acquisition occurs under zero contingency if signaling introduces a contrast, irrespective of whether it protects the target CS from competition with concurrently presented stimuli. Signaling fails to maintain conditioned responding when it does not introduce this contrast. Thus, the introduction of contrast may be the critical factor responsible for acquisition to a target CS when extra USs are signaled.

\section{REFERENCES}

Ayres, J. J. B., Benedict, J. O., \& WiTcher, E. S. (1975). Systematic manipulation of individual events in a truly random control in rats. Joumal of Comparative \& Physiological Psychology, 88, 97-103.
BALSAM, P. D. (1982). Bringing the background to the foreground: The role of contextual cues in autoshaping. In M. Commons, R. Herrnstein, \& A. Wagner (Eds.), The Harvard symposium on the quantitative analysis of behavior: Acquisition processes (pp. 145-171). Cambridge, MA: Ballinger.

Brandon, S. E. (1981). Key-light-specific associations and factors determining key pecking in noncontingent schedules. Journal of Experimental Psychology: Animal Behavior Processes, 7, 348-361.

DURLACH, P. J. (1983). Effect of signaling intertrial unconditioned stimuli in autoshaping. Journal of Experimental Psychology: Animal Behavior Processes, 9, 374-389.

DURLACH, P. J. (1984). The effect of intertrial conditioned stimuli in autoshaping. Quarterly Journal of Experimental Psychology, 36B, 353-369.

DWECK, C. S., \& W AGNer, A. R. (1970). Situational cues and correlation between CS and US as determinants of the conditioned emotional response. Psychonomic Science, 18, 145-147.

FARLEY, J. (1980). Automaintenance, contrast and contingencies: Effects of local vs. overall and prior vs. impending reinforcement context. Learning \& Motivation, 11, 19-48.

Gamzu, E. R., \&illiams, D. R. (1973). Associative factors underlying the pigeon's key pecking in autoshaping procedures. Journal of the Experimental Analysis of Behavior, 19, 225-232.

GiBBON, J. (1981). The contingency problem in autoshaping. In C. M. Locurto, H. S. Terrace, \& J. Gibbon (Eds.), Autoshaping and conditioning theory (pp. 285-308). New York: Academic Press.

GibBON, J., \& BALSAM, P. (1981). Spreading association in time. In C. M. Locurto, H. S. Terrace, \& J. Gibbon (Eds.), Autoshaping and conditioning theory (pp.219-253). New York: Academic Press.

JENKINS, H. M. (1984). Time and contingency in classical conditioning. In J. Gibbon \& L. Allan (Eds.), Timing and time perception (pp. 242-253). New York: New York Academy of Sciences.

Jenkins, H. M., BARnes, R. A., \& BARRERA, F. J. (1981). Why autoshaping depends on trial spacing. In C. M. Locurto, H. S. Terrace, \& J. Gibbon (Eds.), Autoshaping and conditioning theory (pp. 255284). New York: Academic Press.

JenkINS, H. M., \& LAMBos, W. A. (1983). Tests of two explanations of response elimination by noncontingent reinforcement. Animal Learning \& Behavior, 11, 302-308.

JENKINS, H. M., ShATTUCK, D. (1981). Contingency in fear conditioning: A reexamination. Bulletin of the Psychonomic Society, 17, 159-162.

Kaplan, P. S. Hearst, E. (1982). Bridging temporal gaps between CS and US in autoshaping: Insertion of other stimuli before, during, and after CS. Joumal of Experimental Psychology: Animal Behavior Processes, 8, 187-203.

LoLoRDO, V. M., RANDich, A. (1981). Effects of experience of electric shock upon subsequent conditioning of an emotional response: Associative and non-associative accounts. In P. Harzem \& $M$. Zeiler (Eds.), Predictability, correlation, and contiguity (pp. 247-285). New York: Wiley.

Mackintosi, N. J. (1975). A theory of attention: Variations in the associability of stimuli with reinforcement. Psychological Review, 82, 276-298.

Pearce, J. M., \& Hall, G. (1980). A model for Pavlovian learning: Variations in the effectiveness of conditioned but not of unconditioned stimuli. Psychological Review, 87, 532-552.

Rescorla, R. A. (1972). Informational variables in Pavlovian conditioning. In G. H. Bower (Ed.), The psychology of learning and motivation (Vol. 6, pp. 1-46). New York: Academic Press.

RescoRLA, R. A. (1982). Effect of a stimulus intervening between CS and US in autoshaping. Joumal of Experimental Psychology: Animal Behavior Processes, 8, 131-141.

R. A. (1984). Associations between Pavlovian CSs and context. Journal of Experimental Psychology: Animal Behavior Processes, 10, 195-204.

Rescorla, R. A. (1985). Conditioned inhibition and facilitation. In R. Miller \& N. Spear (Eds.), Information processing in animals: Conditioned inhibition (pp, 299-326). Hillsdale, NJ: Erlbaum.

Rescorla, R. A., Colwill, R. M. (1983). Within-compound as- 
sociations in unblocking. Journal of Experimental Psychology: Animal Behavior Processs, 9, 390-400.

Rescorla, R. A., \& Durlach, P. J. (1981). Within-event learning in Pavlovian conditioning. In N. E. Spear \& R. R. Miller (Eds.), Information processing in animals: Memory mechanisms (pp. 81-111). Hillsdale, NJ: Erlbaum.

Rescorla, R. A., \& Wagner, A. R. (1972). A theory of Pavlovian conditioning: Variations in the effectiveness of reinforcement and nonreinforcement. In A. H. Black \& W. F. Prokasy (Eds.), Classical conditioning II: Current research and theory (pp. 64-99). New York: Appleton-Century-Crofts.
WAGNER, A. R. (1978). Expectancies and the priming of STM. In S. H Hulse, H. Fowler, \& W. K. Honig (Eds.), Cognitive processes in animal behavior (pp. 177-209). Hillsdale, NJ: Erlbaum.

Wagner, A. R., \& Rescorla, R. A. (1972). Inhibition in Pavlovian conditioning: Application of a theory. In R. A. Boakes \& M. S. Halliday (Eds.), Inhibition and learning (pp. 301-336). London: Academic Press.

(Manuscript received September 24, 1985; revision accepted for publication January $21,1986$. 